Review

\title{
Pyrethroid effects on freshwater invertebrates: A meta-analysis of pulse exposures
}

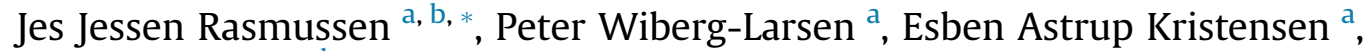 \\ Nina Cedergreen ${ }^{\mathrm{b}}$, Nikolai Friberg ${ }^{\mathrm{a}}$ \\ a Aarhus University, Department of Bioscience, Vejlsøvej 25, 8600 Silkeborg, Denmark \\ ${ }^{\mathrm{b}}$ University of Copenhagen, Department of Plant and Environmental Sciences, Thorvaldsensvej 40, 1871 Frederiksberg C, Denmark
}

\section{A R T I C L E I N F O}

\section{Article history:}

Received 3 June 2013

Received in revised form

7 August 2013

Accepted 20 August 2013

\section{Keywords:}

Pyrethroids

Macroinvertebrates

Environmentally realistic exposure

Meta-analysis

Effect thresholds

Risk assessment

\begin{abstract}
A B S T R A C T
Pyrethroids are widely used insecticides that may seriously harm aquatic organisms. Being strongly hydrophobic, pyrethroids in solution occur only in short pulses but may be retained in sediments for longer periods. Consequently, most studies consider the chronic exposure of sediment dwelling organisms. We collected data from 16 studies to determine effect thresholds for stream macroinvertebrates exposed to short pyrethroid pulses evaluating lethal and sublethal ecologically relevant endpoints. Dose-response models showed EC50 for lethality, functional and behavioural endpoints down to $1 / 100,1 / 100$ and $1 / 1000$ of the 48 h LC50 for Daphnia magna, respectively. The results indicate that the overall sensitivity of stream macroinvertebrates to pyrethroids may be higher than previously believed. This review shows the relevance of incorporating data on sublethal endpoints and appropriate post-exposure observation periods in future studies. The current risk assessment procedures and the higher tier approach are discussed in the light of our results.
\end{abstract}

(c) 2013 Elsevier Ltd. All rights reserved.

\section{Introduction}

The use of pyrethroid insecticides has increased considerably over the past two decades, and they have become one of the most frequently used classes of insecticides for controlling pests in a wide variety of crops (Spurlock and Lee, 2008). Intensive arable farming in combination with dense stream networks, which generates a tight connectivity between land and stream, are likely to facilitate an increasing diffuse pollution with pyrethroids.

Pyrethroids are very toxic to non-target aquatic organisms and arthropods are particularly sensitive (Van Wijngaarden et al., 2005; Maund, 2009). Pyrethroids are also highly hydrophobic compounds $\left(\log K_{\mathrm{OW}}>5\right)$ that rapidly dissipate from the water phase and adsorb to mineral and organic particles in both suspension and in sediments (Oudou and Hansen, 2002; Liu et al., 2004). After sedimentation of the particle-pyrethroid complexes, they may persist as sorption complexes with the settled particles for several subsequent months (Gan et al., 2005). Pyrethroids are primarily transported to streams via surface runoff and through tile drains during heavy precipitation events (Kronvang et al., 2003; Schulz,

\footnotetext{
* Corresponding author.

E-mail address: jr@dmu.dk (J.J. Rasmussen).
}

2004). The preferential transport routes and physicochemical properties of pyrethroids concomitantly limit their occurrence in soluble form in recipient streams to a few hours. A comprehensive body of research shows that the bioavailability of particleassociated pyrethroids is reduced compared to pyrethroids in the aqueous phase (e.g. Yang et al., 2006; You et al., 2008; Cui et al., 2010), and for these reasons, several authors have argued that pyrethroid contamination in freshwater systems is relevant mostly for sediment-dwelling organisms (e.g. Hill, 1989; Schleier and Peterson, 2013). Nevertheless, there is also evidence that very short pulses (few hours) of pyrethroids in the aqueous phase are capable of producing both acute and long term effects in stream macroinvertebrates (Liess and Schulz, 1996; Schulz and Liess, 2001; Rasmussen et al., 2008; Nørum et al., 2010).

The aim of this review was to determine effect thresholds for stream macroinvertebrates exposed to short pyrethroid pulses evaluating both lethal and sublethal ecologically relevant endpoints. We compiled existing literature on effects of pulse exposures of aqueous phase pyrethroids on stream macroinvertebrates using microcosm and mesocosm approaches. Freshwater macroinvertebrates were selected because they constitute the most sensitive group of organisms in relation to insecticides in freshwater ecosystems, and changes in macroinvertebrate community structure has been shown to strongly correlate with diffuse source 
pesticide pollution in the field (Liess and von der Ohe, 2005; Schäfer et al., 2012). In fact, the investigations of Liess and von der Ohe (2005) and Schäfer et al. (2012) lend support to the idea that short-term exposure to concentrations that are 100 to 10,000 times lower than the $48 \mathrm{~h} \mathrm{LC} 50_{D}$. magna can cause long term effects at the level of ecosystems. The low thresholds for community effects were partly proposed to be caused by a series of sublethal effects, such as changed interactions between a species and its environment and reduced fitness, which are not readily captured by standard single species mortality tests. This review sheds light on the sensitivity and importance of relevant sublethal endpoints providing new insight into the sensitivity of different traits that can be used to better understand effects on macroinvertebrate communities in the field. We subdivided endpoints into mortality, behavioural endpoints, life-cycle endpoints and functional endpoints and evaluated their sensitivities to pyrethroid exposure separately.

\section{Materials and methods}

\subsection{Literature search}

The search for available literature was undertaken in March and April, 2013 by searching the online scientific reference databases Web of Science and Google Scholar. The search was performed using the topic key words: "freshwater or aquatic" AND "*invertebrate" AND "pyrethroid or insecticide" producing 344 hits. The search was repeated replacing the latter with specific names of active ingredients: *cyhalothrin, *permethrin, *fenvalerate, bifenthrin and tau-fluvalinate providing 18 additional references. The references were downloaded to Endnote $\mathrm{X} 5$, and titles and abstracts were assessed for applicability.

\subsection{Selection of literature and data}

To strictly focus on environmentally realistic exposure scenarios and species that are natural parts of the lotic ecosystems, the following selection criteria were applied to the collected literature: 1 ) exposure of test organisms should not exceed
$4 \mathrm{~h} ; 2$ ) only stream macroinvertebrate species or assemblages are considered (thus not zooplankton species such as D. magna, since these are more lentic species and not commonly found in lotic environments) and 3) controlled exposure scenarios only (micro- and mesocosms). In studies addressing pulse exposures with particleassociated pyrethroids, only data on exposure without particles was collected, because the sorption to particles may reduce the bioavailability and thus ecological effects. In studies addressing multiple stressors (pyrethroids in combination with other stressors), only data on pyrethroid exposure without intentional additional stressors was collected. Data that has been repeatedly used in the literature was identified and only used once in this analysis. In summary, the applied selection criteria were fulfilled by only 16 articles (Table 1 ), and data concerning pesticide compounds (active ingredients), test species, exposure duration, endpoints and time for endpoint registration were collected.

\subsection{Data analysis}

We used the Toxic Unit (TU) approach to standardise the exposure concentrations through which the toxic potential of the substance under consideration is provided in relative terms using Daphnia magna as benchmark organism (LC50 for $48 \mathrm{~h}$ acute toxicity testing). Since all compounds encompassed in this study have similar Modes of Action (MoA), the relative sensitivities of $D$. magna and the studied organisms should remain constant, and we therefore consider the TU approach safe for the purpose of our study. Briefly, the TU for a chemical $i$ is calculated as:

$\mathrm{TU}_{i}=\frac{C_{i}}{\mathrm{LC} 0_{i, j}}$

where $C_{i}$ is the concentration of chemical $i$ and $\mathrm{LC} \mathrm{O}_{i, j}$ is the median lethal concentration for chemical $i$ and species $j$. In the studies that involve the exposure of food items to pyrethroids (Lauridsen et al., 2006; Rasmussen et al., 2012a, 2013), the actual pyrethroid content on the food items were not measured, and the calculated TU values represent nominal aqueous concentrations in the solution in which the food items were exposed. To be further able to compare responses among different types of organisms and endpoints we expressed effects in relative terms (relative divergence from the control scenario).

After the computation of TU, the overall correlation between TU and the relative effect among all taxa and endpoints was checked visually (scatterplot in Supporting Information). Using all data points, we also calculated the mean relative effect and unaffected fractions (based on the protection of $50 \%$ and $90 \%$ of the tested assemblages) for selected TU categories to evaluate the overall effects of pyrethroids.

Table 1

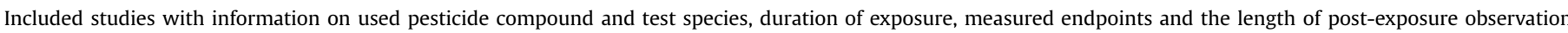
period.

\begin{tabular}{|c|c|c|c|c|c|}
\hline Study & Pesticide & Test organisms & Exposure & Endpoints & $\begin{array}{l}\text { Time for endpoint } \\
\text { registration }\end{array}$ \\
\hline Liess, 1994 & Fenvalerate & Gammarus pulex & $1 \mathrm{~h}$ & Drift & $2 \mathrm{~h}$ post-exposure \\
\hline Liess and Schulz, 1996 & Fenvalerate & Limnephilus lunatus & $1 \mathrm{~h}$ & Survival, emergence success & $84 \mathrm{~d}$ post-exposure \\
\hline Schulz and Liess, 2000 & Fenvalerate & Limnephilus lunatus & $1 \mathrm{~h}$ & Emergence, adult size & $240 \mathrm{~d}$ post-exposure \\
\hline Schulz and Liess, 2001 & Fenvalerate & Limnephilus lunatus & $1 \mathrm{~h}$ & Emergence, adult size & $240 \mathrm{~d}$ post-exposure \\
\hline Cold and Forbes, 2004 & Esfenvalerate & Gammarus pulex & $1 \mathrm{~h}$ & Survival, reproduction & $14 \mathrm{~d}$ post-exposure \\
\hline Forbes and Cold, 2005 & Esfenvalerate & Chironomus riparius & $1 \mathrm{~h}$ & Emergence success & $39 \mathrm{~d}$ post-exposure \\
\hline Lauridsen and Friberg, 2005 & Lambda-cyhalothrin & $\begin{array}{l}\text { Gammarus pulex } \\
\text { Baetis rhodani } \\
\text { Leuctra fusca/digitata }\end{array}$ & $1 \mathrm{~h}$ & Drift (only day drift) & $22 \mathrm{~h}$ post-exposure \\
\hline Heckmann et al., 2005 & Lambda-cyhalothrin & Gammarus pulex & $1 \mathrm{~h}$ & Mortality, reproduction & $4 \mathrm{~d}$ post-exposure \\
\hline Beketov and Liess, 2005 & Esfenvalerate & Cloeon dipterum & $1 \mathrm{~h}$ & Mortality, reproduction & $29 \mathrm{~d}$ post-exposure \\
\hline Lauridsen et al., 2006 & Lambda-cyhalothrin & $\begin{array}{l}\text { Gammarus pulex } \\
\text { Sericostoma personatum } \\
\text { Erpobdella octaculata } \mathcal{E} \\
\text { Leuctra nigra }\end{array}$ & $\begin{array}{l}\text { Indirect } \\
\text { Indirect }\end{array}$ & $\begin{array}{l}\text { Shredding } \\
\text { Predator-prey }\end{array}$ & $\begin{array}{l}7 \mathrm{~d} \text { post-exposure } \\
7 \mathrm{~d} \text { post-exposure }\end{array}$ \\
\hline Rasmussen et al., 2008 & Lambda-cyhalothrin & $\begin{array}{l}\text { Gammarus pulex } \\
\text { Leuctra nigra } \\
\text { Heptagenia sulphurea } \\
\text { Ancylus fluviatilis }\end{array}$ & $90 \mathrm{~min}$ & Shredding grazing & $7 \mathrm{~d}$ post-exposure \\
\hline Beketov and Liess, 2008 & Fenvalerate & $\begin{array}{l}\text { Baetis rhodani } \\
\text { Simuliium latigonium }\end{array}$ & $4 \mathrm{~h}$ & Drift & During exposure \\
\hline Nørum et al., 2010 & Lambda-cyhalothrin & $\begin{array}{l}\text { Gammarus pulex } \\
\text { Heptagenia sulphurea } \\
\text { Leuctra nigra }\end{array}$ & $90 \mathrm{~min}$ & Drift & $1 \mathrm{~h}$ post-exposure \\
\hline Reynaldi et al., 2011 & Fenvalerate & Culex pipiens & $1 \mathrm{~h}$ & Anti-predator behaviour & $5 \mathrm{~h}$ post-exposure \\
\hline Rasmussen et al., 2012a,b & Alpha-cypermethrin & $\begin{array}{l}\text { Gammarus pulex } \\
\text { Halesus radiatus }\end{array}$ & Indirect & Shredding & $26 \mathrm{~d}$ post-exposure \\
\hline Rasmussen et al., 2013 & Lambda-cyhalothrin & $\begin{array}{l}\text { Gammarus pulex } \\
\text { Gammarus pulex } \mathcal{E} \\
\text { Leuctra nigra }\end{array}$ & $\begin{array}{l}90 \mathrm{~min} \\
90 \mathrm{~min}\end{array}$ & $\begin{array}{l}\text { Drift (only without trout) } \\
\text { Predator-prey }\end{array}$ & $\begin{array}{l}\text { During exposure } \\
\text { During exposure }\end{array}$ \\
\hline
\end{tabular}



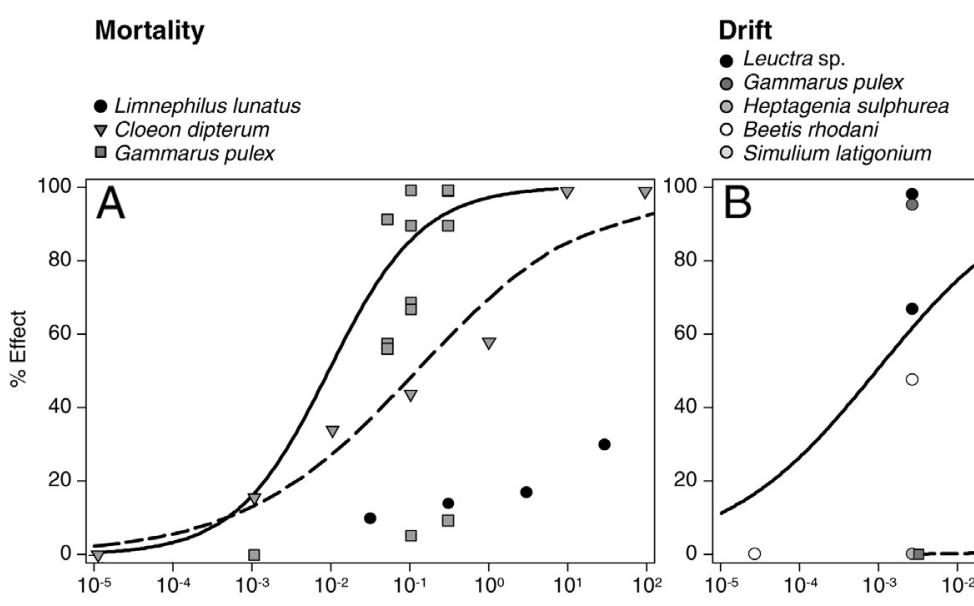

Other behaviour

Leuctra sp.

Heptar

- Beetis rhodani

$\Delta$ Gammarus pulex (precop)
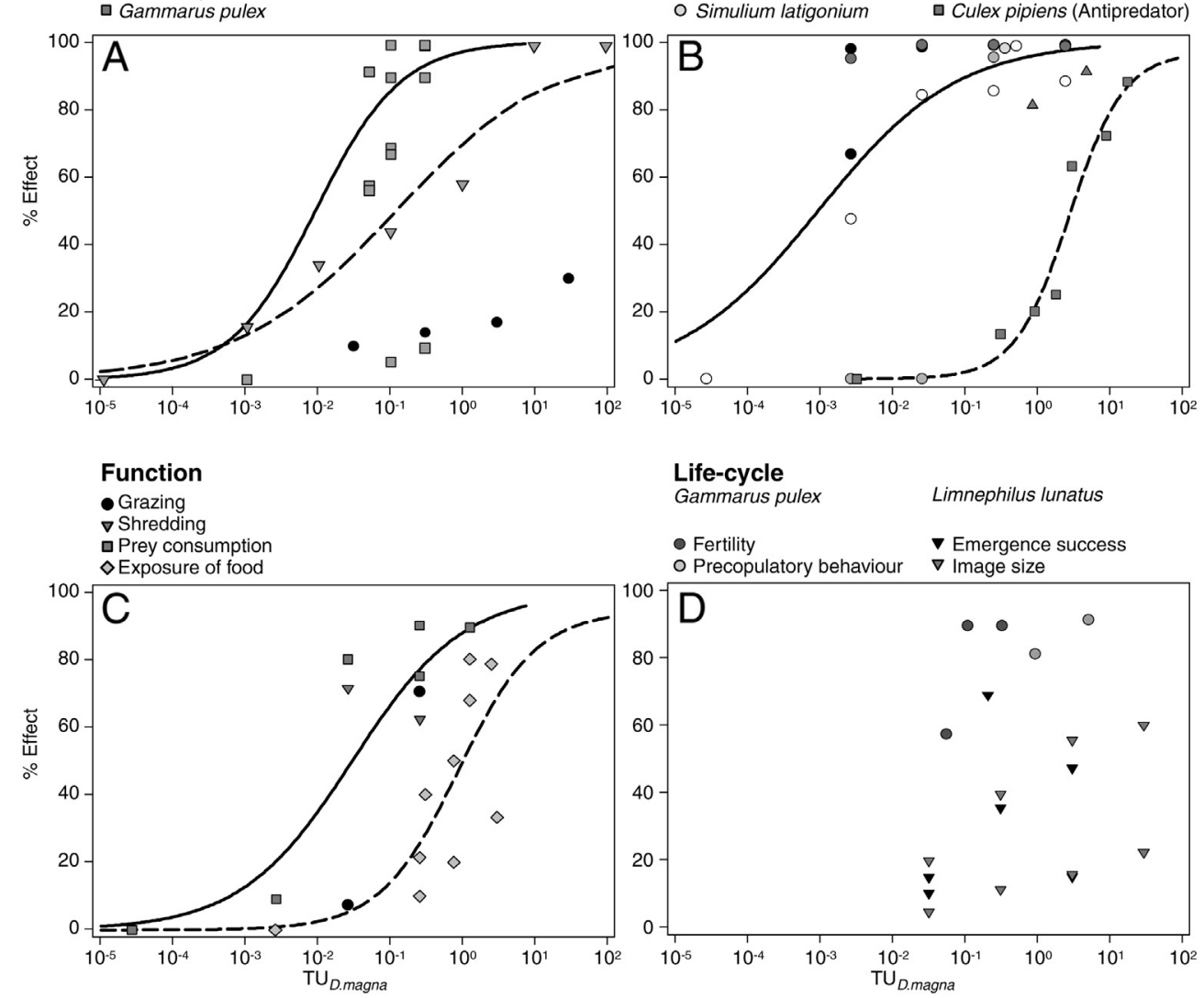

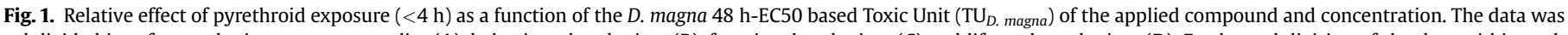

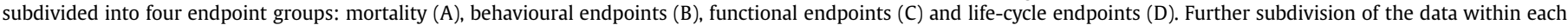

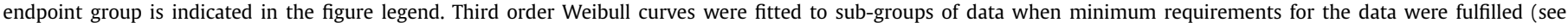

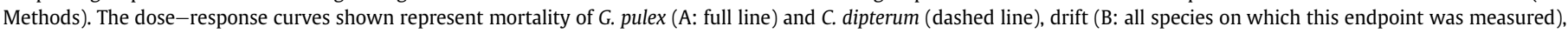
food consumption after direct exposure of macroinvertebrates (C: full line) and exposure of their food (C: dashed line). Obtained EC50 values are presented in Table 2.

Subsequently, we subdivided the data into endpoint groups based on the type of endpoints: mortality, behavioural endpoints, life-cycle endpoints and functional endpoints. Behavioural endpoints included drift activity and active anti-predator behaviour, life cycle endpoints included emergence, fecundity and mating success (pre-copulatory behaviour in Gammarus pulex). Functional endpoints included food consumption (prey organisms, epiphytes and leaves). Within each group, we performed dose-response modelling on all groups and selected sub-groups of the data in the free software $\mathrm{R}$ (version 2.13.1) using 3rd order Weibull functions. These functions were used for fitting to force the models to range between no effect and full effect. However, we restricted the computation of dose-response models to data sets that included at least six data points with at least one data point $>80 \%$ effect and one data point $<10 \%$ effect. Moreover, we added a data point representing unaffected controls at a TU value two orders of magnitudes below the TU corresponding to the lowest relative effect.

\section{Results and discussion}

\subsection{Summary of collated data}

The collected studies addressing environmentally realistic exposure scenarios and naturally occurring stream macroinvertebrate species in controlled micro- or mesocosm set-ups cover fourteen different test species, four different pyrethroids and a comprehensive series of biological responses measured during exposure and up to eight months post-exposure. Not surprisingly, direct comparison of all measured types of responses to the $\mathrm{TU}_{D \text {. magna }}$ did not provide much meaningful information due to the excessive variation in the data set owed to: different sensitivities of tested species (von der Ohe and Liess, 2004); range of biological responses; difference in length of applied postexposure observation periods (Supplementary Material, Fig. S1).

\subsection{Endpoint sensitivity}

Subdividing the biological response data into four endpoint specific groups; mortality, life-cycle, behavioural and functional (food consumption by grazers, shredders and predators) endpoints, provided increased insight into the sensitivities of different types of responses to pyrethroid exposure (Fig. 1). In terms of mortality (Fig. 1A), data for two of three species fulfilled the criteria for doseresponse modelling. The derived LC50 for the amphipod Gammarus pulex and the mayfly Cloeon dipterum (Table 2) were 100 and 8 times, respectively, lower than the LC50 for D. magna (48 h

Table 2

Summary table for the dose-response models (Fig. 1).

\begin{tabular}{llll}
\hline Category & Test species & EC50 $\left(\mathrm{TU}_{\text {D. magna }}\right)$ & SE \\
\hline Mortality & Gammarus pulex & 0.010 & 0.049 \\
Mortality & Cloeon dipterum & 0.135 & 0.085 \\
Drift & All & 0.001 & 0.001 \\
Anti-predator behaviour & Culex pipiens & 3.611 & 0.230 \\
Functional (direct) & All & 0.032 & 0.024 \\
Functional (indirect) & All & 1.165 & 0.528 \\
\hline
\end{tabular}


exposure) despite the much shorter exposure times of maximum 90 min (Table 2). This implies that pyrethroids are rapidly taken up or adsorbed to an organism which is in accordance with other findings (Maund et al., 2002). This also implies that the prolonged exposure of pyrethroids from hours to days may not increase mortality as much as increasing the exposure concentration as also shown by Schulz and Liess (2000). Mortality in G. pulex and C. dipterum were recorded after $14 \mathrm{~d}$ and $46 \mathrm{~d}$ post-exposure, respectively, but the LC50 recorded immediately after exposure were up to three orders of magnitude higher than those observed after the post-exposure observation period (Cold and Forbes, 2004; Beketov and Liess, 2005). This clearly emphasises the importance of applying sufficient post-exposure observation periods for the proper identification of the toxic potential of pesticides to stream macroinvertebrates. Importantly, Cold and Forbes (2004), additionally, showed that the sensitivity of G. pulex to pyrethroids strongly depends on the timing of the exposure in relation to organismal size and moulting (permeability of the exoskeleton). This is also visible from the large variation in the data where a TU of 0.1 may either cause full mortality or no mortality depending on the life stage of the organism (Fig. 1A). The case-bearing caddisfly Limnephilus lunatus appeared less sensitive to the direct exposure of aqueous phase pyrethroids compared to G. pulex and Cloeon dipterum (Fig. 1A). This might be due to the protective effect of the case, which the larvae are able to seal with the head and pronotum, thereby inhibiting the passive uptake of pyrethroids.

Behavioural endpoints were clearly dominated by drift activity, and the macroinvertebrate drift responses to pyrethroid exposure were generally characterised by an all-or-nothing response (Fig. 1B). All tested species use drift as a dispersal mechanism and active escape behaviour (e.g. from predators or anthropogenic threats; Brittain and Eikeland, 1988). There is a large body of field based evidence that drift is used actively by normally drift-active species as escape mechanism during insecticide pollution (e.g. Muirhead-Thomson, 1978; Wallace et al., 1989; Heckmann and Friberg, 2005). We found a very low EC50 for drift activity, 1000 fold below the $48 \mathrm{~h} \mathrm{LC50}{ }_{D \text {. magna }}$ (Table 2 ), and the shape of the data (Fig. 1B) suggests that practically all individuals of drift-active species congruently respond with active escape behaviour to concentrations that are close to the chemical detection limit (i.e. 0.6$8 \mathrm{ng}$ per sediment sample or per L water sample; Woudned and Oros, 2006). Controlled field experiments have shown that populations seem to recover within a couple of months after shortterm pyrethroid exposure (e.g. Heckmann and Friberg, 2005). However, in agricultural dominated catchments, the major parts of the headwater streams may be simultaneously, and possibly sequentially, exposed to pesticides during heavy precipitation episodes that initiate the wash-off of pesticides from adjacent fields (e.g. McKnight et al., 2012). Therefore, species colonisation sources from unaffected upstream sections and tributaries may be scarce. This translates into a significant reduction in the recovery potential of contaminated stream sections compared to the mentioned controlled field experiments. Liess and von der Ohe (2005), Schäfer et al. (2012) and von der Ohe and Goedkoop (2013) provide evidence that having unaffected upstream sections does significantly enhance the recolonisation process of contaminated stream sections, whereas the absence of such significantly reduces the recovery potential of downstream sections.

The anti-predator behaviour of Culex pipiens (after a $1 \mathrm{~h}$ pulse of fenvalerate and $5 \mathrm{~h}$ post-exposure observation period) was much less sensitive than the drift response of other macroinvertebrates (Table 2, Fig. 1B). Reynaldi et al. (2011) showed that the main effect was observed only after the post-exposure observation period, since there was no effect of fenvalerate on the anti-predator behaviour of $C$. pipiens immediately after exposure. It should be noted that $C$. pipiens primarily occurs in lakes and ponds and only rarely in the stagnant parts of streams.

The functional responses of stream macroinvertebrates to pyrethroid exposure include the consumption of prey-organisms, leaf litter and periphyton during exposure and up to 28 days postexposure. Despite relatively limited data availability and large variation in test-organisms and feeding functional groups among the included studies, relatively robust dose-response models were produced $\left(R^{2} \geq 0.63\right)$ for the direct (exposure of macroinvertebrates) or indirect (their food) exposure (Fig. 1C). In all cases investigated, the effect of increased exposure was that feeding activity decreased. The EC50 for the functional endpoints (direct exposure) was almost 100 times more sensitive than the $48 \mathrm{~h} \mathrm{LC} 0_{D \text {. magna }}$ emphasising the high sensitivity of such long term effects (Table 2). The EC50 for the functional endpoints using indirect exposure was less sensitive and close to the $48 \mathrm{~h} \mathrm{LC} 50_{D \text {. magna. }}$. This shows that the direct exposure of organisms has higher impact on food consumption than the indirect exposure which is supported by e.g. Coats et al. (1989) who found that fenvalerate was six-fold more toxic to mosquito larvae by passive uptake through the cuticula compared to dietary exposure routes. This is perhaps not surprising, since aqueous phase pyrethroids are rapidly taken up through the surface of the exoskeleton in macroinvertebrates (due to high $\log K_{\mathrm{ow}}$ of pyrethroids), whereas the uptake of pyrethroids sorbed to ingested food items is more unclear. Uptake rates through the digestive system will probably depend on chemically and enzymatically mediated desorption of active ingredients from food items inside the digestive tract (Widenfalk et al., 2008; Ahrens et al., 2001). Nevertheless, in the field, macroinvertebrates and their food will likely be simultaneously exposed, but the combined effects of short-term direct and a long term indirect exposure were unfortunately not encompassed in the assembled studies. However, Bundschuh et al. (2012) found that the combined effects of indirect and direct exposure to pyrethroids ( $24 \mathrm{~h}$ exposure) may be more than additive. The observed reduction in food acquisition as response to pyrethroid exposure also has long-term perspectives since reduced energy intake in combination with increased metabolic activity (due to detoxification of pyrethroids and damage repair) will render less energy available for growth and reproduction (Zubrod et al., 2011). Relevantly, pesticide mediated effects on organic matter processing have been reported from the field, although the results may be confounded by other anthropogenic stressors acting in congruence (Schäfer et al., 2007; Rasmussen et al., 2012b).

Data on life-cycle responses represents only two species with the majority of data points relating to the caddis fly Limnephilus lunatus that was found to be relatively insensitive to the aqueous phase pyrethroids (and less so than G. pulex). Moreover, the data requirements for dose-response modelling were not fulfilled, and therefore no dose-response curves were produced. We found no obvious systematic trend in the data (Fig. 1D).

\subsection{Field relevance of results}

The detections of aqueous phase pyrethroids in field surveys are practically restricted to strategic water sampling, in which samples are only taken when the likelihood of their occurrence in the water is high i.e. during run-off events. Pyrethroid concentrations up to $6.2 \mu \mathrm{g} \mathrm{L}^{-1}$ have been measured, but most quantifiable detections remain below $0.1 \mu \mathrm{g} \mathrm{L}^{-1}$ (see review by Schulz, 2004). Detection frequencies of pyrethroids in water samples are often low due to their periodic occurrence in streams and their high log $K_{\mathrm{OW}}$ values enforcing sorption to sediments and sedimenting particles (Gan et al., 2005). However, strategic sediment sampling, i.e. undertaken after the spraying season, has revealed high detection frequencies of pyrethroids ( $>40 \%$ of collected samples) documenting 
their frequent occurrence in agricultural streams (Kuivila et al., 2012; Nanos et al., 2012). These findings may additionally suggest that the low detection frequency of pyrethroids in routine stream water sampling is not only due to the phase distribution of pyrethroids, but rather reflect the shortcomings of water sampling strategies not being able to catch the relevant pulse exposures (Stehle et al., 2013). Based on event-triggered water sampling, pyrethroid concentrations often exceed the computed LC50 and EC50 values for behavioural and functional endpoints in our study (Schulz, 2004; Nanos et al., 2012). Coupling this to the high occurrence frequency of pyrethroids in agricultural streams, we suggest that pyrethroids are to be considered a highly relevant group of toxic compounds not only for sediment-dwelling macroinvertebrates but also for e.g. swimmers and crawlers.

\subsection{Extrapolation of results to the field scenario}

The coupling of low computed threshold concentrations for relevant ecological endpoints with the field based evidence of pyrethroid concentrations exceeding LC50 and EC50 values is somewhat concerning, especially as actual field detections of pyrethroids are likely to only be the tip of the iceberg. Considering that swimming/crawling stream macroinvertebrates will be subject to both acute direct and subsequent more chronic and indirect exposure in the field and that the summed response will incorporate all endpoints addressed in this meta-analysis, the overall sensitivity of the stream macroinvertebrates to pyrethroids may be higher than previously believed. Lending support to our findings, Liess and von der Ohe (2005) and Schäfer et al. (2012) showed that field based EC50 thresholds for pesticide induced changes in stream macroinvertebrate communities were three to four orders of magnitudes below the $48 \mathrm{~h} \mathrm{LC} 50_{D}$. magna. Whereas the findings of Liess and von der Ohe (2005) and Schäfer et al. (2012) are strictly correlative (increased concentrations of pesticides are often autocorrelated with several other stressors such as nutrients, particle transport and habitat degradation), our meta-analysis provides evidence that a few hours of pyrethroid exposure alone is sufficient to produce severe and long term effects at concentrations in the range at which community changes has been observed in the field.

Surely, one central question when utilising micro- and mesocosm approaches is to what extent the artificial environmental conditions mimic natural conditions and thus the applicability of results to reality. Limiting the biological complexity or scale dependent behaviour of the species components limits the ecological relevance and applicability to real stream ecosystems (Cooper and Barmuta, 1993). However, important common denominators for all studies included in this meta-analysis are the environmentally realistic exposure scenarios (exposure duration) and all nominal pyrethroid concentrations are within the range of previous field observations. Moreover, all endpoints used in this meta-analysis are derived from the single exposure to aqueous pyrethroids, and in reality biota will likely be exposed to a more complex set of anthropogenic disturbances. We therefore argue that the compiled micro- and mesocosm studies - if anything likely underestimate the potential effects of pyrethroids in the field, since the exposure of one stressor is often found to increase the sensitivity to other stressors (Relyea and Hoverman, 2006). However, a large fraction of pyrethroids may be particle bound even when they enter streams which likely render them less bioavailable and therefore decreasing the effect on the current-exposed biota.

\subsection{Consequences for the risk assessment of pyrethroids}

Considering the mean relative effect across all endpoint types, disregarding taxa, exposure scenario, and post-exposure

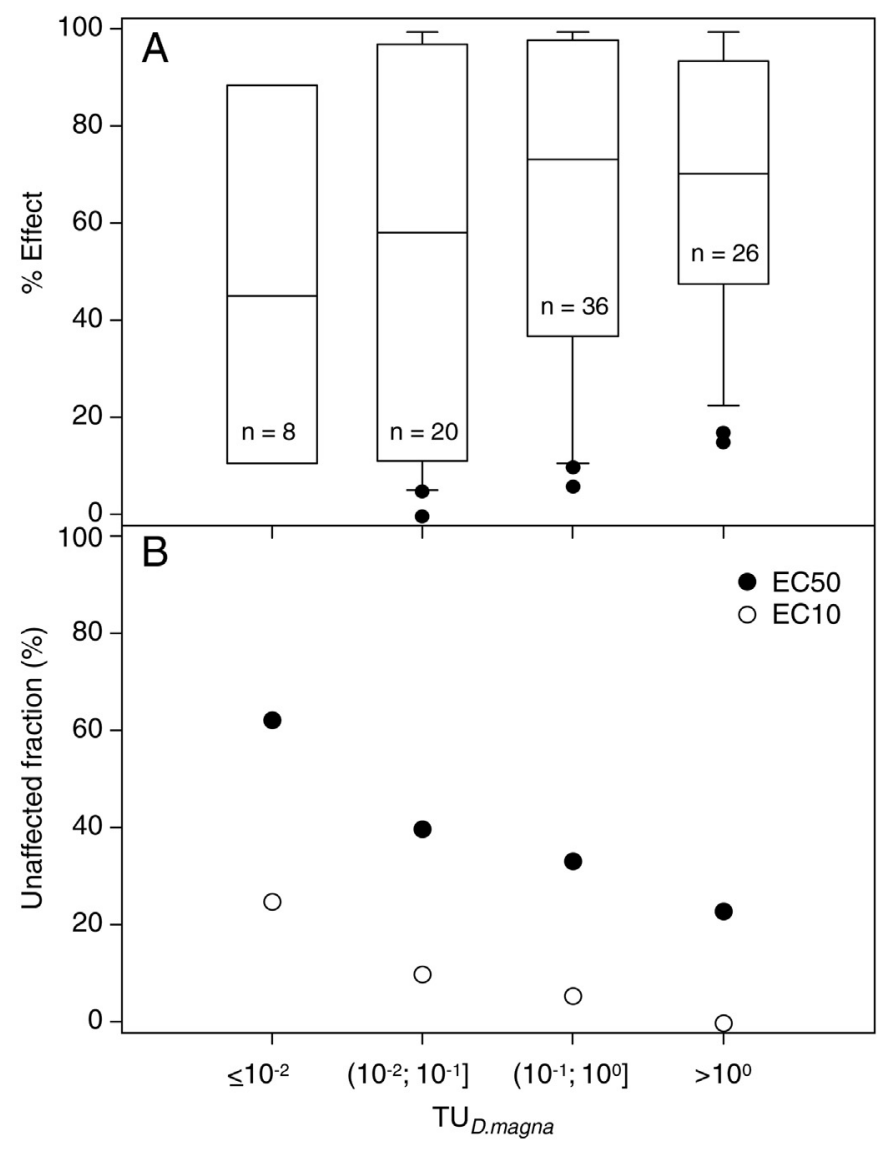

Fig. 2. Boxplot of the average relative effect of pyrethroid exposure across all measured endpoints (A) and the calculated unaffected fraction (based on the protection of either $50 \%$ or $90 \%$ of the exposed macroinvertebrate assemblage; B). The data was grouped according to the calculated $\mathrm{TU}_{D}$. magna of the exposure. Boxplot boundaries indicate the 25th and 75th percentile, and error bars indicate SE of the mean.

observation period, shows substantial adverse effects at least two orders of magnitudes below the $48 \mathrm{~h} \mathrm{LC50}{ }_{D}$. magna $(F i g .2 \mathrm{~A}$ ). For endpoints related to exposure, concentrations below $1 / 100$ of the $48 \mathrm{~h} \mathrm{LC50}$. magna the frequency of any endpoint remaining below the EC10 was only $20 \%$ (Fig. 2B). The fact that a blunt compilation of effect data still provides relatively clear results and the fact that the results suggest clear effects below the normally applied threshold concentration for no effects $\left(1 / 100\right.$ of the $48 \mathrm{~h} \mathrm{LC} 50_{D}$. magna $)$ is concerning.

Compounds such as pyrethroids will often be risk assessed at higher tiers due to their high toxicity, using chronic data on susceptible organisms and sometimes supplemented by microcosm studies if the chronic studies suggest a potential risk (European Commission, 2002). Microcosm studies, however, are associated with high variance in the data. Often the Coefficients of Variation (CV: stdev/mean) on various population density measures of control treatments are in the range of $30-50 \%$ (Sanderson, 2002). This means that the lowest detectable difference between control and treatment when using 3-4 replicates per treatment is often more than $50 \%$ (Sanderson et al., 2009). In other words, if it is a protection goal for a given EPA to tolerate maximum a $25 \%$ reduction in the population density of a sensitive species (after X weeks recovery), the calculated NOEC ( $t$-test between control and treated using the required 4 replicates, a CV of $30 \%$ of both controls and treated populations and an $\alpha=0.05$ ) only states with $27 \%$ certainty (power of the test) that there is actually no difference between control and treatment. The power of the test will decrease with 
increasing variance of the selected endpoint and decreasing number of replicates. Hence, the higher tier tests are statistically quite weak tests forming the final basis of pesticide risk assessments, if they are not efficiently backed up by laboratory tests, where more replicates and less variance can typically be obtained. The present study shows that the sensitivity to pyrethroid pulses of some sublethal endpoints (e.g. functional performance) rather closely resemble the sensitivity of macroinvertebrate community structure monitored in the field in response to joint pesticide load estimates (Schäfer et al., 2012). We therefore suggest that functional endpoints (grazing, shredding and prey consumption (Fig. 1C, Table 2)), could be used as supplements to other higher tier tests in the risk assessment of pyrethroid pesticides. The strength of this approach would be that effects on ecosystem functioning translates easily into the likely consequence of pyrethroid exposure for ecosystem services, which could support water management decision.

\subsection{Research challenges and needs}

Several authors have called for a paradigm shift in ecotoxicology involving the use of more traditional ecological methods for the proper interpretation of large scale ecotoxicological effect assessments (Relyea and Hoverman, 2006; Beketov and Liess, 2012). Such a paradigm shift is, however, obstructed given the scarcity of proper exposure characterisations. Most studies to date have been directed towards the sediment-associated fraction (e.g. Mehler et al., 2011; Kuivila et al., 2012; Weston et al., 2013). This meta-analysis documents the importance of the concomitant consideration and characterisation of the aqueous and mobile fractions of pyrethroids in streams which should be increasingly addressed in the future.

Our meta-analysis also highlights the crucial importance of using sufficiently long post-exposure observation periods when addressing effects of pulsed pyrethroid exposure in order to capture the full effects. Especially, the functional performances of species appeared surprisingly sensitive when addressed using appropriately long post-exposure observation periods. Pyrethroid impacts on the functional performance of species may be a corner stone for the proper understanding of long term effects. Loss of functional performance may have cascading effects reducing the amount of available energy for growth and reproduction and therefore also the chances for an organism to successfully reproduce and compete for space and food. A more robust assessment of such indirect, but ecologically highly relevant, effects is critical for the proper characterisation of community sensitivity and effects. Using relevant endpoints and endpoint combinations (e.g. functional and behavioural) and exposure types (direct and indirect) are likely equally important for the successful acquisition of such knowledge.

\section{Acknowledgements}

We thank all persons and funding bodies involved in the studies analysed in this paper. JJR was funded by a grant from the Carlsberg Foundation (Grant No. 2012_01_0107). We specifically thank Jørn Kirkegaard, and the Danish EPA pesticide research programme, for giving us the insights that made this publication possible. Moreover, we thank two anonymous reviewers for positive feedback and constructive comments on an earlier draft of the manuscript.

\section{Appendix A. Supplementary data}

Supplementary data related to this article can be found at http:// dx.doi.org/10.1016/j.envpol.2013.08.012.

\section{References}

Ahrens, M.J., Hertz, J., Lamoureux, E.M., Lopez, G.R., McElroy, A.E., Brownawell, B.J., 2001. The role of digestive surfactants in determining bioavailability of sediment-bound hydrophobic organic contaminants to 2 deposit-feeding polychaetes. Mar. Ecol. Prog. Ser. 212, 145-157.

Beketov, M.A., Liess, M., 2005. Acute contamination with esfenvalerate and food limitation: chronic effects on the mayfly, Cloeon dipterum. Environ. Toxicol. Chem. 24, 1281-1286.

Beketov, M.A., Liess, M., 2008. Potential of 11 pesticides to initiate downstream drift of stream macroinvertebrates. Arch. Environ. Contam. Toxicol. 55, 247-253.

Beketov, M.A., Liess, M., 2012. Ecotoxicology and macroecology - time for integration. Environ. Pollut. 162, 247-254.

Brittain, J.E., Eikeland, T.J., 1988. Invertebrate drift - a review. Hydrobiologia 166, 77-93.

Bundschuh, M., Appeltauer, A., Dabrunz, A., Schulz, R., 2012. Combined effect of invertebrate predation and sublethal pesticide exposure on the behavior and survival of Asellus aquaticus (Crustacea; Isopoda). Arch. Environ. Contam. Toxicol. 63, 77-85.

Coats, J.R., Symonik, D.M., Bradbury, S.P., Dyer, S.D., Timson, L.K., Atchison, G.J., 1989 Toxicology of synthetic pyrethroids in aquatic organisms: an overview. Environ. Toxicol. Chem. 8, 671-679.

Cold, A., Forbes, V.E., 2004. Consequences of a short pulse of pesticide exposure for survival and reproduction of Gammarus pulex. Aquat. Toxicol. 67, 287-299.

Cooper, S.D., Barmuta, L.A., 1993. Field experiments in biomonitoring. In: Rosenberg, D.M., Resh, V.H. (Eds.), Freshwater Biomonitoring and Benthic Macroinvertebrates. Chapman \& Hall, London, pp. 341-399.

Cui, X., Hunter, W., Yang, Y., Chen, Y., Gan, J., 2010. Bioavailability of sorbed phenanthrene and permethrin in sediments to Chironomus tentans. Aquat. Toxicol. 98, 83-90.

European Commission, 2002. Guidance Document of Aquatic Ecotoxicology in the Context of the Directive 91/414/EEC. Sanco/3268/2001 rev. 4 (final) ed. European Commission Health \& Consumer Protection Directorate-General, pp. $1-62$.

Forbes, V.E., Cold, A., 2005. Effects of the pyrethroid esfenvalerate on life-cycle traits and population dynamics of Chironomus riparius - importance of exposure scenario. Environ. Toxicol. Chem. 24, 78-86.

Gan, J., Lee, S.J., Liu, W.P., Haver, L., Kabashima, J.N., 2005. Distribution and persistence of pyrethroids in runoff sediments. J. Environ. Qual. 34, 836-841.

Heckmann, L.H., Friberg, N., 2005. Macroinvertebrate community response to pulse exposure with the insecticide lambda-cyhalothrin using in-stream mesocosms. Environ. Toxicol. Chem. 24, 582-590.

Heckmann, L.H., Friberg, N., Ravn, H.W., 2005. Relationship between biochemical biomarkers and pre-copulatory behaviour and mortality in Gammarus pulex following pulse-exposure to lambda-cyhalothrin. Pest Manag. Sci. 61, 627-635.

Hill, I.R., 1989. Aquatic organisms and pyrethroids. Pestic. Sci. 27, 429-465.

Kronvang, B., Iversen, H.L., Løkke, H., Vejrup, K., Mogensen, B.B., Hansen, A., Hansen, L.B., 2003. Pesticides in streams and subsurface drainage water within two arable catchments in Denmark: pesticide application, concentration, transport and fate. Pestic. Res., 141.

Kuivila, K.M., Hladik, M.L., Ingersoll, C.G., Kemble, N.E., Moran, P.W., Calhoun, D.L., Nowell, L.H., Gilliom, R.J., 2012. Occurrence and potential sources of pyrethroid insecticides in stream sediments from seven U.S. metropolitan areas. Environ. Sci. Technol. 46, 4297-4303.

Lauridsen, R.B., Friberg, N., 2005. Stream macroinvertebrate drift response to pulsed exposure of the synthetic pyrethroid lambda-cyhalothrin. Environ. Toxicol. 20, $513-521$.

Lauridsen, R.B., Kronvang, B., Friberg, N., 2006. Occurrence of sediment-bound pyrethroids in Danish streams and their impact on ecosystem function. Water Air Soil Pollut. 6, 423-432.

Liess, M., 1994. Pesticide impact on macroinvertebrate communities on running waters in agricultural ecosystems. Verh. Int. Ver. Theor. Angew. Limnol. 25, 2060-2062.

Liess, M., Schulz, R., 1996. Chronic effects of short-term contamination with the pyrethroid insecticide fenvalerate on the caddisfly Limnephilus lunatus. Hydrobiologia 324, 99-106.

Liess, M., von der Ohe, P.C., 2005. Analyzing effects of pesticides on invertebrate communities in streams. Environ. Toxicol. Chem. 24, 954-965.

Liu, W.P., Gan, J.J., Lee, S., Kabashima, J.N., 2004. Phase distribution of synthetic pyrethroids in runoff and stream water. Environ. Toxicol. Chem. 23, 7-11.

Maund, S.J., 2009. The Aquatic Ecotoxicology of the Synthetic Pyrethroids from Laboratory to Landscape (PhD thesis). Wageningen University, p. 188.

Maund, S.J., Hamer, M.J., Lane, M.C.G., Farrelly, E., Rapley, J.H., Goggin, U.M., Gentle, W.E., 2002. Partitioning, bioavailability, and toxicity of the pyrethroid insecticide cypermethrin in sediments. Environ. Toxicol. Chem. 21, 9-15.

McKnight, U.S., Rasmussen, J.J., Kronvang, B., Bjerg, P.L., Binning, P.J., 2012. Integrated assessment of the impact of chemical stressors on surface water ecosystems. Sci. Total Environ. 427-428, 319-331.

Mehler, W.T., Li, H., Ludy, M.J., You, J., 2011. Identifying the causes of sedimentassociated toxicity in urban waterways of the Pearl River delta, China. Environ. Sci. Technol. 45, 1812-1819.

Muirhead-Thomson, R.C., 1978. Lethal and behavioral impact of chlorpyrifos methyl and temephos on select stream macroinvertebrates - experimental studies on downstream drift. Arch. Environ. Contam. Toxicol. 7, 139-147. 
Nanos, T., Boye, K., Kreuger, J., 2012. Results From the Environmental Monitoring of Pesticides (in Swedish), Ekohydrologi. Swedish University of Agricultural Sciences, Uppsala, p. 80.

Nørum, U., Friberg, N., Jensen, M., Pedersen, J., Bjerregaard, P., 2010. Behavioural changes in three species of freshwater macroinvertebrates exposed to the pyrethroid lambda-cyhalothrin: laboratory and stream microcosm studies. Aquat. Toxicol. 98, 328-335.

Oudou, H.C., Hansen, H.C.B., 2002. Sorption of lambda-cyhalothrin, cypermethrin deltamethrin and fenvalerate to quartz, corundum, kaolinite and montmorillonite. Chemosphere 49, 1285-1294.

Rasmussen, J.J., Friberg, N., Larsen, S.E., 2008. Impact of lambda-cyhalothrin on a macroinvertebrate assemblage in outdoor experimental channels: implications for ecosystem functioning. Aquat. Toxicol. 90, 228-234.

Rasmussen, J.J., Monberg, R.J., Baattrup-Pedersen, A., Cedergreen, N., WibergLarsen, P., Strobel, B.W., Kronvang, B., 2012a. Effects of a triazole fungicide and a pyrethroid insecticide on the decomposition of leaves in the presence or absence of macroinvertebrate shredders. Aquat. Toxicol. 118-119, 54-61.

Rasmussen, J.J., Wiberg-Larsen, P., Baattrup-Pedersen, A., Monberg, R.J., Kronvang, B., 2012b. Impacts of pesticides and natural stressors on leaf litter decomposition in agricultural streams. Sci. Total Environ. 416, 148-155.

Rasmussen, J.J., Nørum, U., Wiberg-Larsen, P., Kristensen, E.A., Friberg, N., 2013. Pesticide impacts on predator-prey interactions across two levels of organisation. Aquat. Toxicol. 140-141, 340-345.

Relyea, R., Hoverman, J., 2006. Assessing the ecology in ecotoxicology: a review and synthesis in freshwater systems. Ecol. Lett. 9, 1157-1171.

Reynaldi, S., Meiser, M., Liess, M., 2011. Effects of the pyrethroid fenvalerate on the alarm response and on the vulnerability of the mosquito larva Culex pipiens molestus to the predator Notonecta glauca. Aquat. Toxicol. 104, 56-60.

Sanderson, H., 2002. Pesticide studies: replicability of micro/mesocosms. Environ. Sci. Pollut. Res. 9, 429-435.

Sanderson, H., Laird, B., Brain, R., Wilson, C.J., Solomon, K.R., 2009. Detectability of fifteen aquatic micro/mesocosms. Ecotoxicology 18, 838-845.

Schleier, J.J., Peterson, R.K.D., 2013. A refined aquatic ecological risk assessment for a pyrethroid insecticide used for adult mosquito management. Environ. Toxicol. Chem. 32, 948-953.

Schulz, R., 2004. Field studies on exposure, effects, and risk mitigation of aquatic nonpoint-source insecticide pollution: a review. J. Environ. Qual. 33, 419-448.

Schulz, R., Liess, M., 2000. Toxicity of fenvalerate to caddisfly larvae: chronic effects of 1-vs 10-h pulse-exposure with constant doses. Chemosphere 41, 1511-1517.

Schulz, R., Liess, M., 2001. Toxicity of aqueous-phase and suspended particleassociated fenvalerate: chronic effects after pulse-dosed exposure of Limnephilus lunatus (Trichoptera). Environ. Toxicol. Chem. 20, 185-190.

Schäfer, R.B., Caquet, T., Siimes, K., Mueller, R., Lagadic, L., Liess, M., 2007. Effects of pesticides on community structure and ecosystem functions in agricultura streams of three biogeographical regions in Europe. Sci. Total Environ. 382, $272-285$.

Schäfer, R.B., Von der Ohe, P.C., Rasmussen, J.J., Kefford, B., Beketov, M., Schulz, R., Liess, M., 2012. Thresholds for the effects of pesticides on invertebrate communities and leaf breakdown in stream ecosystems. Environ. Sci. Technol. 46, 5134-5142.

Spurlock, F., Lee, M., 2008. Synthetic pyrethroid use patterns, properties and environmental effects. In: Gan, J., Spurlock, F., Dendley, P., Weston, D.P. (Eds.), Synthetic Pyrethroids. American Chemical Society, Washington DC, pp. 3-25.

Stehle, S., Knäbel, A., Schulz, R., 2013. Probabilistic risk assessment of insecticide concentrations in agricultural surface waters: a critical appraisal. Environ. Monit. Assess. 185, 6295-6310.

Van Wijngaarden, R.P.A., Brock, T.C.M., Van den Brink, P.J., 2005. Threshold levels for effects of insecticides in freshwater ecosystems: a review. Ecotoxicology 14, 355-380.

von der Ohe, P.C., Goedkoop, W., 2013. Distinguishing effects of habitat degradation and pesticide stress on benthic invertebrates using stressor-specific metrics. Sci. Total Environ. 444, 480-490.

von der Ohe, P.C., Liess, M., 2004. Relative sensitivity distribution of aquatic invertebrates to organic and metal compounds. Environ. Toxicol. Chem. 23, 150156.

Wallace, J.B., Lugthart, G.J., Cuffney, T.F., Schurr, G.A., 1989. The impact of repeated insecticidal treatments on drift and benthos of a headwater stream. Hydrobiologia 179, 135-147.

Weston, D.P., Ding, Y., Zhang, M., Lydy, M.J., 2013. Identifying the cause of sediment toxicity in agricultural sediments: the role of pyrethroids and nine seldommeasured hydrophobic pesticides. Chemosphere 90, 958-964.

Widenfalk, A., Lundqvist, A., Goedkoop, W., 2008. Sediment microbes and biofilms increase the bioavailability of chlorpyrifos in Chironomus riparius (Chironomidae, Diptera). Ecotoxicol. Environ. Saf. 71, 490-497.

Woudned, M.B., Oros, D.R., 2006. Quantitative determination of pyrethroids, pyrethrins, and piperonyl butoxide in surface water by high-resolution gas chromatography/high-resolution mass spectrometry. J. Agric. Food Chem. 54, 6957-6962.

Yang, W., Spurlock, F., Liu, W., Gan, J., 2006. Inhibition of aquatic toxicity of pyrethroid insecticides by suspended sediment. Environ. Toxicol. Chem. 25, 19131919.

You, J., Pehkonen, S., Weston, D.P., Lydy, M.J., 2008. Chemical availability and sediment toxicity of pyrethroid insecticides to Hyalella azteca: application to field sediment with unexpectedly low toxicity. Environ. Toxicol. Chem. 27, 2124-2130.

Zubrod, J.P., Bundschuh, M., Feckler, A., Englert, D., Schulz, R., 2011. Ecotoxicological impact of the fungicide tebuconazole on an aquatic decomposer-detritivore system. Environ. Toxicol. Chem. 30, 2718-2724. 